\title{
Sputter deposition technology as a materials engineering
}

\author{
KIYOTAKA WASA \\ Matsushita Electric Industries, Yagumonakamachi, Moriguchi 570, Japan
}

\begin{abstract}
Sputter deposition is currently being widely used in the microelectronics industry for the production of silicon integrated circuits. Recently interest has been focused on sputter deposition as a new materials processing technique. The highly energetic sputtered atoms enhance crystal growth and/or sintering during film growth. This results in lowering of the growth temperature of high temperature materials including cubic diamonds. Single crystals of complex ceramics materials could be prepared by sputter deposition through epitaxial growth process. Atomically controlled deposition using multi-target sputter enables to make man-made superlattice including high- $T_{C}$ superconductors of layered perovskite. At present sputter deposition is one of key materials technologies for the coming century.
\end{abstract}

Keywords. Sputter; thin films; diamonds; PLZT; high- $T_{C}$ superconductors.

\section{Introduction}

Sputter was first observed in a de gas discharge tube by Grove in 1852 . He discovered that the cathode surface of the discharge tube was sputtered by energetic ions from the gas discharge, and cathode materials were deposited on the inner wall of the discharge tube.

At that time sputtering was regarded as an undesirable phenomenon since the cathode and grid in the gas tube were destroyed. However, sputter is available for surface cleaning and etching, thin film deposition, surface and surface layer analysis, and sputter ion sources. At present sputter and sputter deposition are common manufacturing processes for a wide variety of industries. Fundamental technology for sputter and sputter deposition have been reviewed in several publications (Wehner 1955; Chopra 1969; Maissel and Glang 1970; Behrisch 1981; Wasa and Hayakawa 1991).

Recently interest has been focused on sputter deposition as a novel materials processing technique since unique electronics materials could be synthesized by the highly energetic sputter atoms under nonthermal equilibrium conditions. The sputter process shows the possibility of controlled deposition of complex ceramic materials on an atomic scale for future electronic devices.

This paper describes the special features of sputter deposition and offers an overview of recent experimental results on sputter deposition of future electronics materials including diamond, ferroelectric perovskite and high- $T_{c}$ superconductors of layered perovskite.

\section{Feature of sputter deposition}

When a target is bombarded with energetic particles sueh as accelerated ions, surface atoms of the target are sputtered backwards due to collisions between the surface 


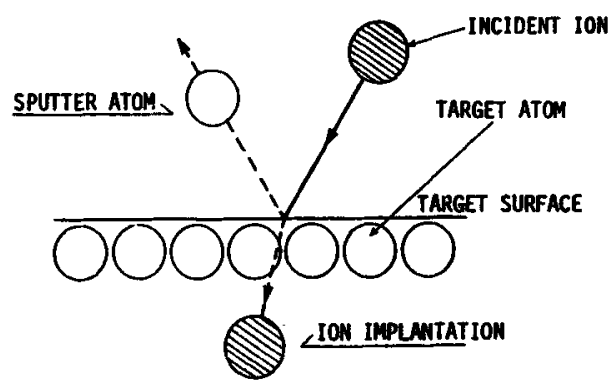

Figure 1. Sputter phenomena.

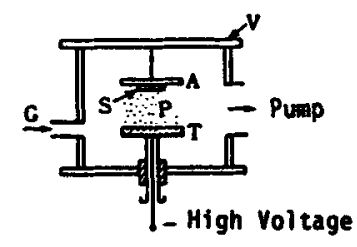

DC-Diode Glow Discharge

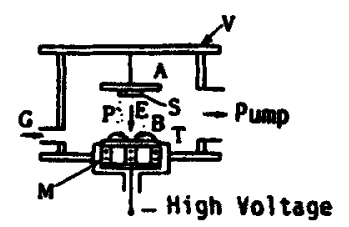

Planer Magnetron

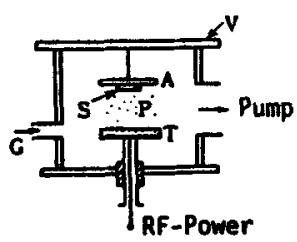

RF-Dlode Grow DIscharge

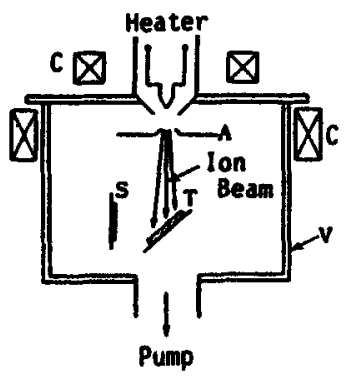

Ion Beam

(A)Anode, ( $T$ ) Target, (V)Vessel, (S)Substrate, (P)P asma, (G)Sputter Gas, (M)Magnet, (E)Electric Field, (B)magnetic Field, (C)Coil

Figure 2. Sputter systems.

atoms and the energetic particles as shown in figure 1 . This phenomenon is called "back-sputter' or simply "sputter".*

Thin films of target material can be deposited on a substrate placed opposite the target by accumulation of the sputter atoms. Typical sputter deposition systems are shown in figure 2 .

Among these sputter systems the simplest model is the dc diode sputter system. The dc sputter system is composed of a pair of planar electrodes. One of the electrodes is a cold cathode and the other the anode. The front surface of the cathode is covered with the target material to be deposited. The substrate is placed on the anode. The sputter chamber is filled with sputter gas, typically Ar gas at 0.1 torr. The glow discharge is maintained under the application of dc voltage between the electrodes. The Ar ions generated in the glow discharge are accelerated at the cathode fall and

\footnotetext{
* When a thin foil is bombarded with energetic particles. some of the scattered atoms transmit through the foil. The phenomena is called 'transmission-sputter.'
} 
cause sputter in the target, resulting in deposition of a thin film on the substrate. In the dc sputter system the target is composed of metal and/or conducting materials, so that the glow discharge is maintained between the electrodes.

By the simple substitution of an insulator for the metal target in the dc sputter discharge system, the sputter discharge cannot be maintained because of the immediate build-up of a surface charge of positive ions on the front side of the insulator. The insulative target can be sputtered directly by the rf-diode sputter system. In the magnetron sputter a magnetic field is superposed on the glow discharge perpendicularly to a direction of an electric field. The electrons in the discharge are trapped in the discharge space, resulting in an increase of ionization probability. This lowers the sputter gas pressure to as low as $10^{-4}$ torr. Low working pressure increases the deposition rate and decreases the impurity concentration involved in the films since the sputter particles traverse the discharge space without collisions. A low working pressure is also attained by the ion beam sputter system, where the incident ions are generated at the ion source. The target is sputtered in a sputter chamber separated from the ion source. In these sputter systems thin films of compounds including oxides or nitrides can be deposited by a reactive sputter from metal targets and/or by a direct sputter from the compound targets.

The sputter process exhibits several interesting features for materials engineering:

(i) A wide variety of materials can be deposited by the sputter process, including high temperature ceramics, since the sputter process is not governed by the thermal evaporation mechanism but by the momentum transfer mechanism.

(ii) The energy of the sputter atoms is of the order of 1 to $30 \mathrm{eV}$, corresponding to temperatures of $10^{4}$ to $10^{5} \mathrm{~K}$. Irradiation of the highly energetic sputtered atoms on the growing surface of thin films raises the temperature at the area of film growth locally. High temperature materials can be synthesized at low temperatures.

(iii) Highly energetic adatoms during film growth induce ultra-high pressure on the growing surface of thin films. Synthesis pressure for ceramic materials synthesized at high pressure is apparently lower in sputter deposition.

(iv) Highly energetic adatoms are quenched during film growth at ultra-high quenching rate $\left(10^{17} \mathrm{~K} / \mathrm{sec}\right)$. Exotic materials could be synthesized by sputter deposition.

(v) Novel materials could be synthesized with ultra-high precision of atomic scale by sputter deposition, including atomically controlled man-made superlattice and/or nanometer composites with quantum size effects.

A variety of ceramic materials have been proposed for electronic devices, including ferroelectric perovskites and high- $T_{c}$ superconductors. These ceramic materials show polycrystalline structure. Production of ceramic materials of single crystalline phase with atomically controlled structure is required for future electronic devices whose operating frequency will be higher than GHz. The novel features of the sputter process meet these requirements.

\section{Interesting sputter processes}

\subsection{Room temperature growth of diamonds}

Natural diamonds grow from carbon underground at depths of $200-300 \mathrm{~km}$, where the growth conditions of high pressure $(50 \mathrm{kbar})$ and high temperature $\left(200^{\circ} \mathrm{C}\right)$ are 


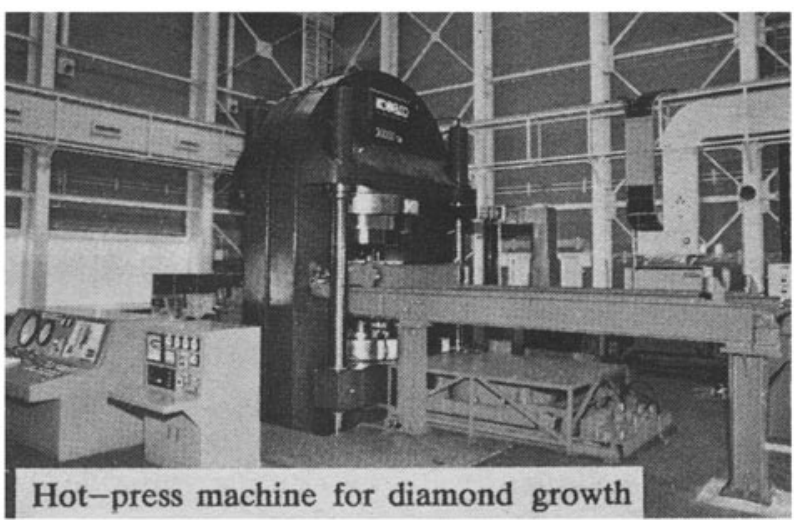

Figure 3. Hot-press machine for the synthesis of cubic diamond which generates $50 \mathrm{kbar}$, $2000^{\circ} \mathrm{C}$.

satisfied. Several attempts have been made to synthesize diamonds under high pressure and high temperature conditions. Hot-pressing using a $30 \mathrm{kton}$ press, as shown in figure 3 , is one of the successful methods to realize the growth conditions of cubic diamonds.

Deposition of energetic carbon atoms shows the possibility of growth of diamonds at room temperature. Aisenberg and Chabot (1971) first tried to deposit thin films of diamond at room temperature by deposition of energetic carbon ions using ion beam deposition. The carbon ions were accelerated at $40 \mathrm{eV}$ by a biased field. The resultant films were transparent with high electrical resistivity. Since their physical properties resemble those of diamonds, this kind of film is called diamond-like carbon (DLC) films. The DLC films may be composed of amorphous carbon with small diamond crystallites dispersed in the amorphous carbon network.

Sputter deposition of diamond at room temperature was first tried by Wasa and Hayakawa (1976) using rf-diode sputter. The sputtered films on glass substrate in $\mathrm{Ar}$ were found to be DLC films.

Diamond crystallites of cubic structure were first deposited at room temperature by the ion beam sputter (Kitabatake and Wasa 1985). The ion beam sputter system used for the preparation of the diamond crystallites is shown in figure 4 . The graphite disk target (purity $5 \mathrm{~N}, 100 \mathrm{~mm}$ in diam.) was bonded to the water-cooled holder. It is expected that irradiation of the surface of the sputtered film during film growth by energetic ions and/or chemically active ions will modify the structural properties of the resultant sputtered films. The ion beam sputters the target and simultaneously bombards the surface of the substrate at grazing angle incidence. It is found that the optical transparency of the sputtered DLC films increases with the addition of hydrogen ions into the ion beams. Bombardment of the substrate with hydrogen ions during the deposition enhances the growth of the diamond structure and reduces the graphite composition. The most interesting phenomenon is that under bombardment of hydrogen ions several diamond crystals grow partially on the DLC films as shown in figure 5. The crystals exhibit the well-defined morphology of cubic diamond and their lattice constant coincides with that of natural cubic diamond.

It is also noted that the incidence angle of the hydrogen ions changes the crystal structure of the sputtered diamond. Decrease of the incident angle has enhanced the 


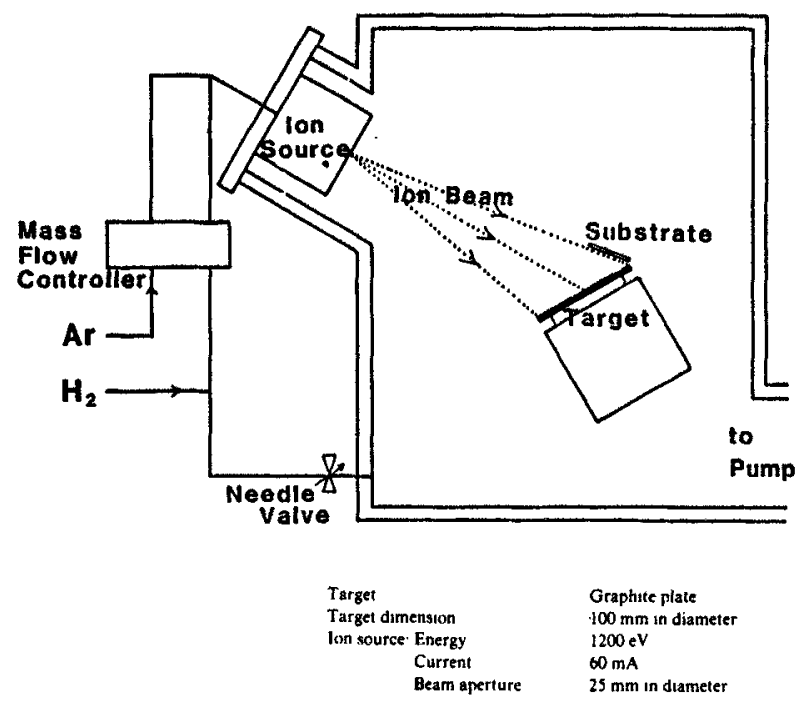

Figure 4. Ion beam sputter for diamond growth.

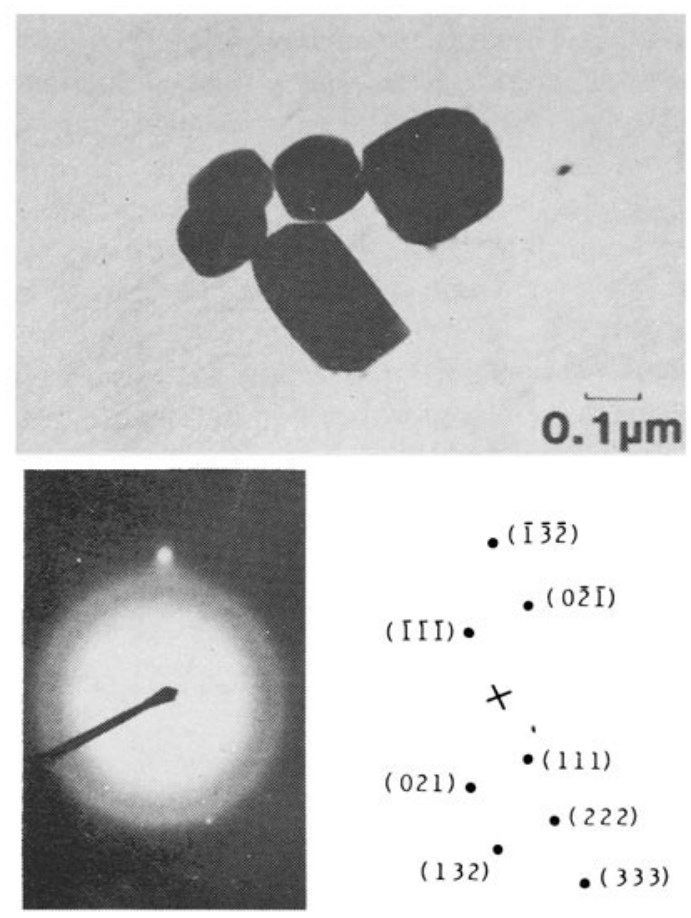

Figure 5. Typical TEM images and electron diffraction pattern of cubic diamond particles.

growth of the hexagonal diamonds shown in figure 6. The [111] direction of cubic diamond corresponds to the [0001] direction of hexagonal diamond. The $60^{\circ}$ rotated bonding of the four-fold coordinated carbon along the [111] direction of cubic diamond coincides with that of hexagonal diamond along [111] (Kitabatake and Wasa 1988). 

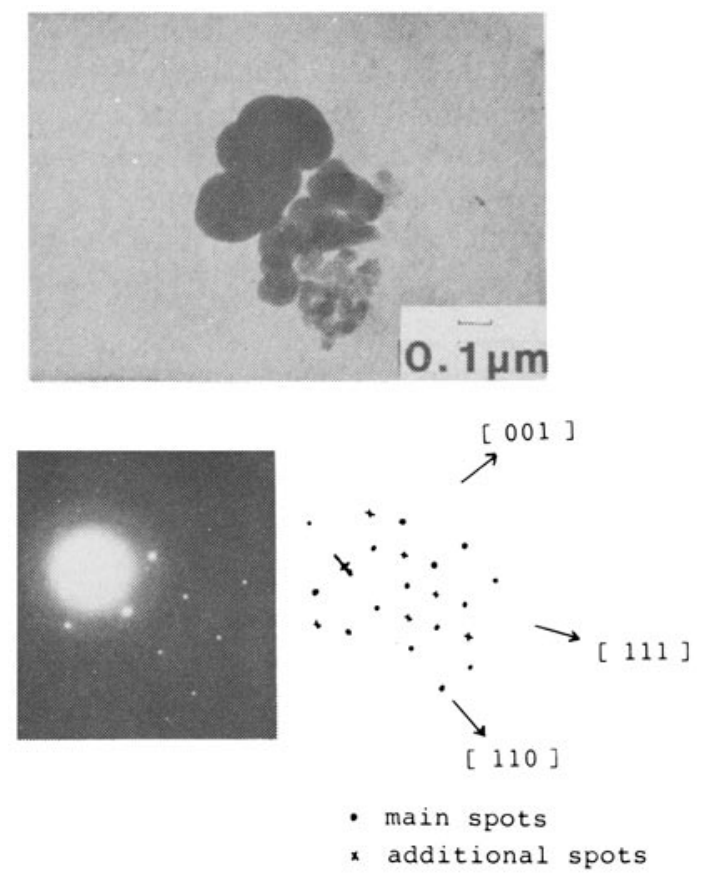

Figure 6. TEM images and electron diffraction pattern of hexagonal diamond particles.

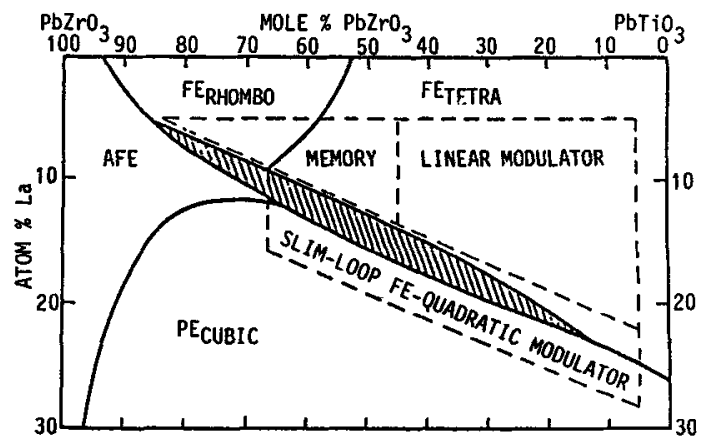

Figure 7. Phase diagram of PLZT ceramics (Haertling and Land 1971).

\subsection{Single crystal PLZT thin films}

The PLZT $\left[(\mathrm{Pb}, \mathrm{La})(\mathrm{Zr}, \mathrm{Ti}) \mathrm{O}_{3}\right]$ ceramics are known as high density polycrystalline ceramics with optically transparent property. Figure 7 shows the phase diagram of $\operatorname{PLZT~}(x / y / z)\left[\left(\mathrm{Pb}_{1-x} \mathrm{La}_{x}\right)\left(\mathrm{Zr}_{y} \mathrm{Ti}_{z}\right)_{1-x / 4} \mathrm{O}_{3}\right]$ ceramics (Haertling and Land 1971). The enhanced grain growth due to the addition of $\mathrm{La}$ into PZT $\left[\mathrm{Pb}(\mathrm{Zr}, \mathrm{Ti}) \mathrm{O}_{3}\right]$ and the improved sintering process, including the purification of source materials and hot-pressing, have reduced the structural imperfection of the residual voids and optical scattering centres of impurity. Deposition of PLZT ceramics could result in high density pure PLZT with controlled structural properties.

The basic deposition process of PLZT thin films is shown in figure 8 . Several processes have been proposed for the deposition, including evaporation (Oikawa and 


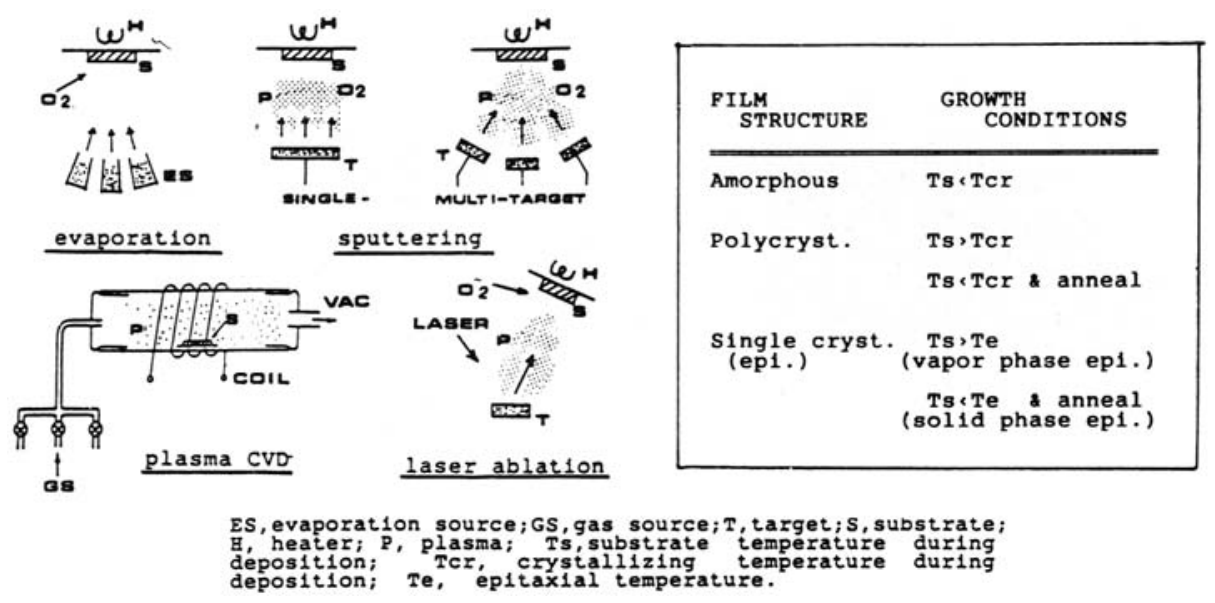

Figure 8. Basic deposition process of PLZT thin films.

Toda 1989), sputtering (Adachi et ai 1983), laser ablation (Otsubo et al 1990), and chemical vapour deposition (Nakagawa et al 1982). These processes are essentially similar to the case of the high- $T_{C}$ superconductors of layered perovskite (Adachi and Wasa 1990). Chemical composition, crystal phase, crystal imperfections and/or stress included are considered for controlled deposition of PLZT thin films.

The structural properties of PLZT thin films are controlled by the deposition conditions as shown in figure 8. Thin films of amorphous phase are deposited at the substrate temperature $T_{\mathrm{s}}$ below the crystallizing temperature $T_{\mathrm{cr}} . T_{\mathrm{cr}}$ for perovskite oxides is empirically around $500-700^{\circ} \mathrm{C}$. In some cases different crystal phases are observed at substrate temperature below $T_{c r}$; in the case of $\mathrm{PbTiO}_{3}$ the pyrochlore phase $\left(\mathrm{PbTi}_{3} \mathrm{O}_{7}\right)$ has been observed.

Thin films of polycrystalline phase are deposited at $T_{\mathrm{s}}>T_{\mathrm{cr}}$. The polycrystalline phase can also be obtained by deposition of amorphous films followed by postannealing at a temperature above $T_{\mathrm{cr}}$. Thin films of a single crystal are deposited on a single crystal substrate at substrate temperature above the epitaxial temperature $T_{\mathrm{e}}$ due to a vapour phase epitaxy. The amorphous and/or polycrystalline phase are converted into the single crystalline phase by the post-annealing at a temperature above $T_{e}$ owing to a solid phase epitaxy. For deposition of single phase perovskite, the stoichiometric composition must be kept in the deposited films. Sapphire, $\mathrm{SrTiO}_{3}$ and $\mathrm{MgO}$ are commonly used as substrate for the epitaxial growth (Adachi et al 1986).

Figure 9 shows a typical electron diffraction pattern and crystal orientation for the sputtered thin films of single crystal PLZT epitaxially grown on (0001) sapphire. The epitaxial relations are as follows:

(111)PLZT//(0001) sapphire,

[110]PLZT//[1010] sapphire.

The epitaxial temperature is around $600^{\circ} \mathrm{C}$.

Figure 10 shows the temperature dependence of the dielectric constant of PLZT thin films epitaxially grown on sapphire substrates with various sputtering target compositions. The dielectric properties of these epitaxial thin films are measured by the deposition of interdigital electrodes on the film surface as shown in figure 11 . 

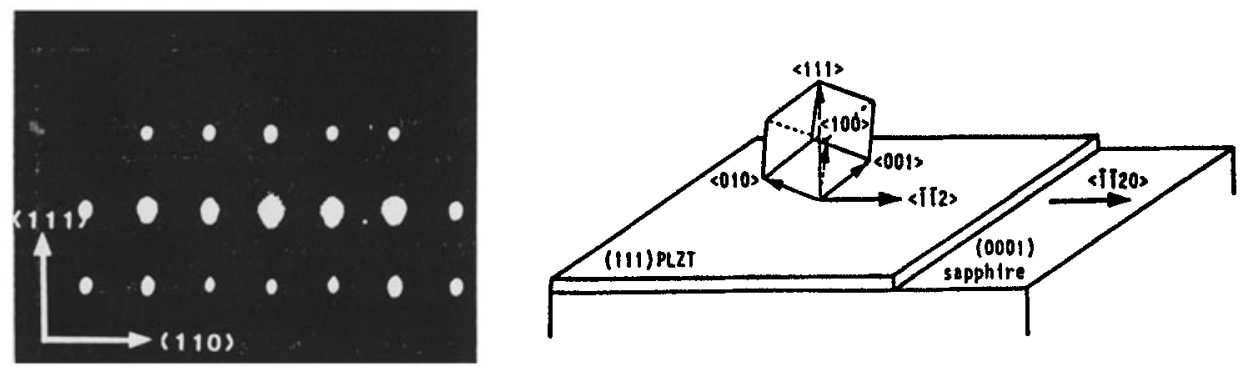

Figure 9. Typical electron diffraction pattern and crystal orientation of sputtered epitaxial PLZT (20/0/100) thin films of $0.4 \mu \mathrm{m}$ thickness on (0001) sapphire; target, PLZT (28/0/100).
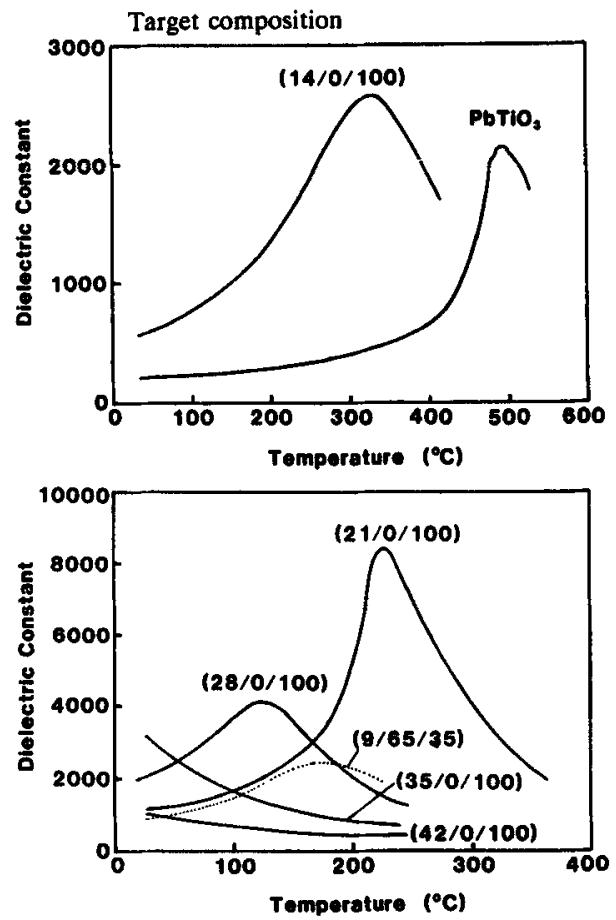

Figure 10. Temperature dependence of dielectric constant for epitaxial PLZT thin films of $0.4 \mu \mathrm{m}$ thickness on (0001) sapphire measured at $100 \mathrm{kHz}$.

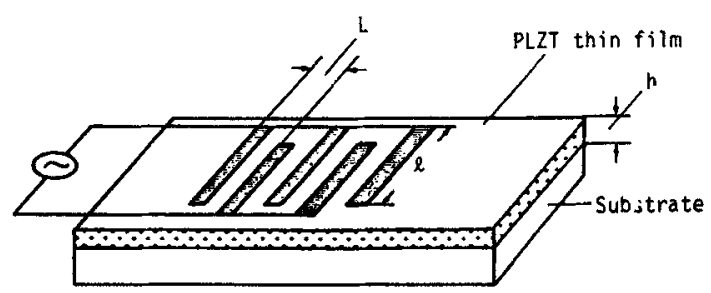

Figure 11. Al interdigital electrodes (IDE) for the measurement of dielectric properties of epitaxial PLZT thin films. Thin film dielectric constant is calculated from the measured capacitance $C$ of the Al IDE on top of the film using the approximation

$$
C=\operatorname{Knl}\left[\left(\varepsilon_{S}+1\right)+\left(\varepsilon_{f}-\varepsilon_{S}\right)[1-\exp (-4 \cdot 6 h / L)]\right],
$$

where $\varepsilon_{S}$ is the dielectric constant of the substrate $\left(\varepsilon_{S}=10\right), h$ the thin-film thickness $(h=0.33 \mu \mathrm{m}), L$ the centre-to-centre spacing between adjacent electrodes $(L=6 \mu \mathrm{m}), n$ the number of electrode strips $(n=160), l$ the length of the fingers of electrodes $\left(l=720 \times 10^{-6} \mathrm{~m}\right)$, and $K$ the constant given by the structure of electrodes $\left(K=4.53 \times 10^{-12}\right)$. 


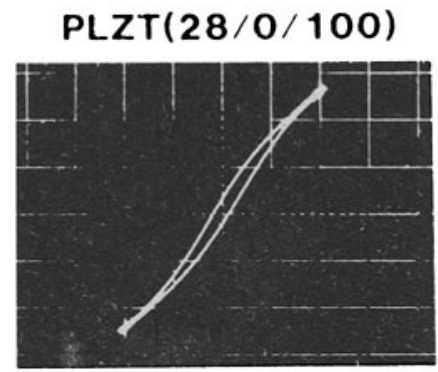

RT

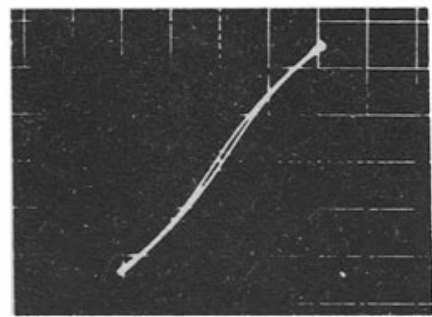

$100^{\circ} \mathrm{C}$

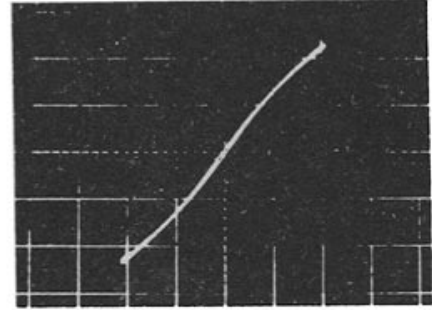

$130^{\circ} \mathrm{C}$

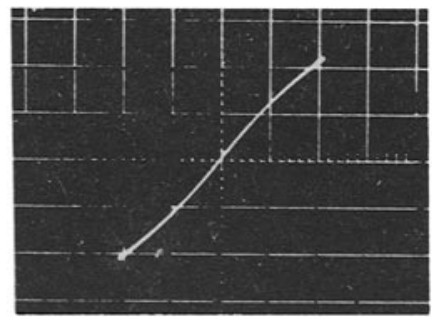

$160^{\circ} \mathrm{C}$

Figure 12. Temperature dependence of D-E hysteresis loop for PLZT (20/0/100) thin films of $0.4 \mu \mathrm{m}$ thickness on (0001) sapphire measured at $60 \mathrm{~Hz}$. Horizontal, $5 \mathrm{~V} /$ div.; vertical, $3 \times 10^{-9} \mathrm{C} / \mathrm{div}$.

Table 1. Dielectric properties of sputtered PLZT thin films of $0.4 \mu \mathrm{m}$ thickness.

\begin{tabular}{lrrrrr}
\hline & \multicolumn{2}{c}{ Thin films } & \multicolumn{2}{c}{ Ceramics } \\
\cline { 2 - 5 } Target composition & $\varepsilon^{*}$ & $T_{c}\left({ }^{\circ} \mathrm{C}\right)$ & $\varepsilon^{*}$ & $T_{c}\left({ }^{\circ} \mathrm{C}\right)$ \\
\hline PbTiO $_{3}$ & 370 & 490 & 230 & 490 \\
PLZT $(0 / 65 / 35)$ & 450 & 275 & & 365 \\
PLZT (7/65/35) & 480 & 260 & 1570 & 150 \\
PLZT $(9 / 65 / 35)$ & 710 & 240 & 4650 & 85 \\
PLZT $(11 / 65 / 35)$ & 630 & 220 & 4100 & 70 \\
PLZT $(14 / 65 / 35)$ & 380 & 220 & 1450 & 50 \\
PLZT $(14 / 0 / 100)$ & 600 & 290 & 1200 & 220 \\
PLZT $(21 / 0 / 100)$ & 1300 & 225 & 2000 & 100 \\
PLZT $(28 / 0 / 100)$ & 1800 & 120 & 2000 & -100 \\
PLZT $(42 / 0 / 100)$ & 1100 & & & \\
\hline
\end{tabular}

* Measured at $10 \mathrm{kHz}, \mathrm{RT}$.

These films show the D-E hysteresis curve as shown in figure 12 . The peak of the dielectric constant will correspond to the Curie temperature $T_{c}$, since the D-E hysteresis disappears above the peak.

Table 1 shows the typical dielectric properties for sputtered films of $\mathrm{Pb}-\mathrm{Ti}-\mathrm{O}_{3}$ families prepared by single target system. Increase of La decreases the $T_{C}$, as in the ceramics. The $T_{C}$ of the thin films are higher than those of the ceramics, which is mainly attributed to a shift in the composition of sputtered thin films from the target composition.

The optically transparent PLZT thin films also have high electro-optic coefficient. Figure 13 shows a typical birefringence shift as a function of electric field. The 


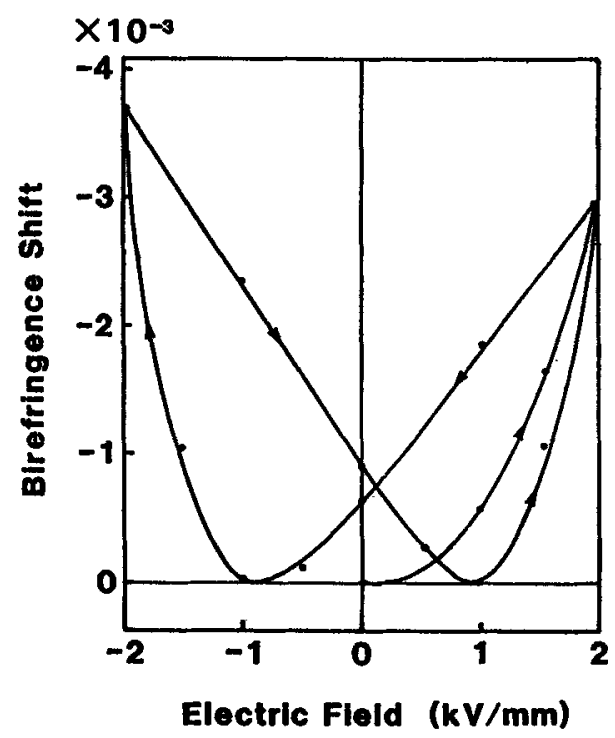

Figure 13. Typical birefringence shift as a function of electric field for sputtered epitaxial PLZT $(9 / 65 / 35)$ thin films of $0-4 \mu \mathrm{m}$ thickness on (0001) sapphire.

characteristics show a quadratic curve governed by the Kerr effect. The electro-optic coefficient is almost the same as those of PLZT bulk ceramics of similar composition.

However, there are essential differences between the growth of thin films and ceramic sintering as described in the section on sputter probably due to the presence of the substrate and/or the irradiation of energetic atoms. The growth mechanism of the thin films will partly be governed by the bulk ceramic, as in the sintering process. A detailed understanding of the differences between ceramic sintering and thin film growth will be necessary for proper sputter deposition of these complex ceramics.

\subsection{Atomically controlled deposition}

High- $T_{C}$ superconductors of $\mathrm{Bi}-\mathrm{Sr}-\mathrm{Ca}-\mathrm{Cu}-\mathrm{O}$ (Bi-system), shown in figure 14 , exhibit the layered perovskite structure comprising $\mathrm{Cu}-\mathrm{O}$ layer with apical oxygen which forms the two-dimensional array of $\mathrm{Cu}-\mathrm{O}$ pyramids or octahedra. The superconducting transition temperature and/or the superconducting phase are governed by the numbers of $\mathrm{Cu}-\mathrm{O}$ layers as indicated in table 2 (Wasa et al 1991). Although the high- $T_{c}$ superconductors were first synthesized in the form of sintered ceramics, the sintering process did not allow control of the superconducting phase. The thin film process achieves phase control of high- $T_{c}$ superconductors.

Several deposition processes are proposed for deposition of high- $T_{C}$ superconductors of Bi-system, including sputter, reactive evaporation, chemical vapour deposition and laser ablation. It is known that $\mathrm{Bi}_{2} \mathrm{Sr}_{2} \mathrm{Ca}_{1} \mathrm{Cu}_{2} \mathrm{O}_{x}\left(2212 \mathrm{Bi}\right.$-system, $T_{C}=80 \mathrm{~K}$, low $T_{C}$ phase) is stable below $860^{\circ} \mathrm{C}$ in oxygen. $\mathrm{Bi}_{2} \mathrm{Sr}_{2} \mathrm{Ca}_{2} \mathrm{Cu}_{3} \mathrm{O}_{x}(2223$ Bi-system, $T_{c}=110 \mathrm{~K}$, high- $T_{c}$ phase) is stable above $860^{\circ} \mathrm{C}$. The sintered ceramics comprise the 2212 low $-T_{C}$ phase, although the virgin composition is kept at the $\mathrm{Bi} 2223 \mathrm{high}-T_{C}$ phase. 
(MO) ${ }_{2} \mathrm{~A}_{2} \mathrm{CuO}_{\text {, }}$

1) $\mathrm{Bi}_{2} \mathrm{Sr}_{2} \mathrm{Cu}_{1} \mathrm{O}_{6}$

2) $\mathrm{Tl}_{2} \mathrm{Ba}_{2} \mathrm{Cu}_{1} \mathrm{O}_{6}$

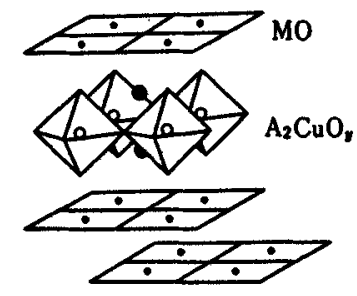

$\mathrm{M}=\mathrm{Bi}, \mathrm{Tl} \quad n=1,2 \quad \mathrm{~A}=\mathrm{Sr}, \mathrm{Ba}$

$\mathrm{T}_{\mathrm{c}}=7-20 \mathrm{~K}(\mathrm{M}=\mathrm{Bi})$

$=20-80 \mathrm{~K}(\mathrm{M}=\mathrm{Tl})$
(MO), $\mathrm{A}_{2} \mathrm{CaCu}_{2} \mathrm{O}$,

1) $\mathrm{Bi}_{2} \mathrm{Sr}_{2} \mathrm{Ca}_{1} \mathrm{Cu}_{2} \mathrm{O}_{8}$

2) $\mathrm{Tl}_{2} \mathrm{Ba}_{2} \mathrm{Ca}_{3} \mathrm{Cu}_{2} \mathrm{O}_{6}$
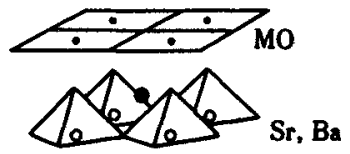

- $\mathrm{Ca}$

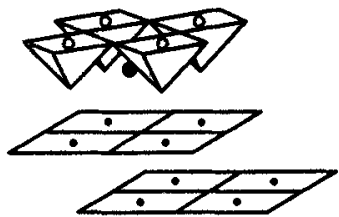

$\mathrm{M}=\mathrm{Bi}, \mathrm{T}] \quad n=1,2 \quad \mathrm{~A}=\mathrm{Sr}, \mathrm{Ba}$

$T_{\mathrm{c}}=85 \mathrm{~K}(\mathrm{M}=\mathrm{Bi})$

$=105 \mathrm{~K}(\mathrm{M}=\mathrm{Tl})$
(MO) $)_{4} \mathrm{~A}_{2} \mathrm{Ca}_{2} \mathrm{Cu}_{3} \mathrm{O}$,

1) $\mathrm{Bi}_{2} \mathrm{Sr}_{2} \mathrm{Ca}_{2} \mathrm{Cu}_{3} \mathrm{O}_{10}$

2) $\mathrm{Tl}_{2} \mathrm{Ba}_{2} \mathrm{Ca}_{2} \mathrm{Cu}_{3} \mathrm{O}_{10}$

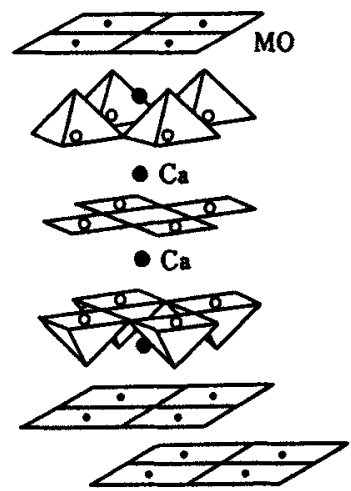

$M=B i, T) \quad n=1,2 \quad A=S r, B a$

$T_{\mathrm{c}}=110 \mathrm{~K}(\mathrm{M}=\mathrm{Bi})$

$=125 \mathrm{~K}(\mathrm{M}=\mathrm{TI})$

Figure 14. Structure of layered perovskite high- $T_{c}$ superconductors.

Table 2. High- $T_{c}$ superconductors.

\begin{tabular}{|c|c|c|}
\hline & $T_{c}(\mathrm{~K})$ & Date \\
\hline \multicolumn{3}{|l|}{ Bi-system } \\
\hline \multicolumn{3}{|l|}{$\mathrm{Bi}_{2} \mathrm{O}_{2} \cdot 2 \mathrm{SrO} \cdot(n-1) \mathrm{CaO} \cdot n \mathrm{CuO}_{2}$} \\
\hline $\mathrm{Bi}_{2} \mathrm{Sr}_{2} \mathrm{CuO}_{6}$ & $7-22$ & 1987.5 \\
\hline $\mathrm{Bi}_{2} \mathrm{Sr}_{2} \mathrm{CaCu}_{2} \mathrm{O}_{8}$ & 80 & 1988.1 \\
\hline $\mathrm{Bi}_{2} \mathrm{Sr}_{2} \mathrm{Ca}_{2} \mathrm{Cu}_{3} \mathrm{O}_{10}$ & 110 & 1988.3 \\
\hline $\mathrm{Bi}_{2} \mathrm{Sr}_{2} \mathrm{Ca}_{3} \mathrm{Cu}_{4} \mathrm{O}_{12}$ & 90 & 1988.9 \\
\hline \multicolumn{3}{|l|}{ Tl-system } \\
\hline \multicolumn{3}{|c|}{$\mathrm{Tl}_{2} \mathrm{O}_{2} \cdot 2 \mathrm{BaO} \cdot(n-1) \mathrm{CaO} \cdot n \mathrm{CuO}_{2}$} \\
\hline $\mathrm{T}_{2} \mathrm{Ba}_{2} \mathrm{CuO}_{6}$ & $20-90$ & 1987.12 \\
\hline $\mathrm{Tl}_{2} \mathrm{Ba}_{2} \mathrm{CaCu}_{2} \mathrm{O}_{8}$ & 105 & 1988.2 \\
\hline $\mathrm{Tl}_{2} \mathrm{Ba}_{2} \mathrm{Ca}_{2} \mathrm{Cu}_{3} \mathrm{O}_{10}$ & 125 & 1988.3 \\
\hline \multicolumn{3}{|l|}{$\mathrm{TIO} \cdot 2 \mathrm{BaO} \cdot(n-1) \mathrm{CaO} \cdot n \mathrm{CuO}_{2}$} \\
\hline $\mathrm{TlBa}_{2} \mathrm{CaCu}_{2} \mathrm{O}_{7}$ & $70-80$ & 1988.5 \\
\hline $\mathrm{TlBa}_{2} \mathrm{Ca}_{2} \mathrm{Cu}_{3} \mathrm{O}_{9}$ & $110-116$ & 1988.5 \\
\hline $\mathrm{TlBa}_{2} \mathrm{Ca}_{3} \mathrm{Cu}_{4} \mathrm{O}_{11}$ & 120 & 1988.5 \\
\hline $\mathrm{TlBa}_{2} \mathrm{Ca}_{4} \mathrm{Cu}_{5} \mathrm{O}_{13}$ & $<120$ & 1988.5 \\
\hline
\end{tabular}

Sputter deposition at high substrate temperature stabilizes formation of the high- $T_{C}$ phase. Figure 15 shows typical results obtained by the magnetron diode sputter with single target. It is seen that the high- $T_{c}$ phase has been stabilized at substrate temperature around $800^{\circ} \mathrm{C}$. The resistivity-temperature curve corresponds to the single high- $T_{C}$ phase. However, TEM images have suggested that there exists intergrowth of the different superconducting phases. The presence of intergrowth is also confirmed by the spreading skirt observed in the X-ray diffraction pattern at low angle (002) peak around $4^{\circ}$ and (0014) peak around $34^{\circ}$. 


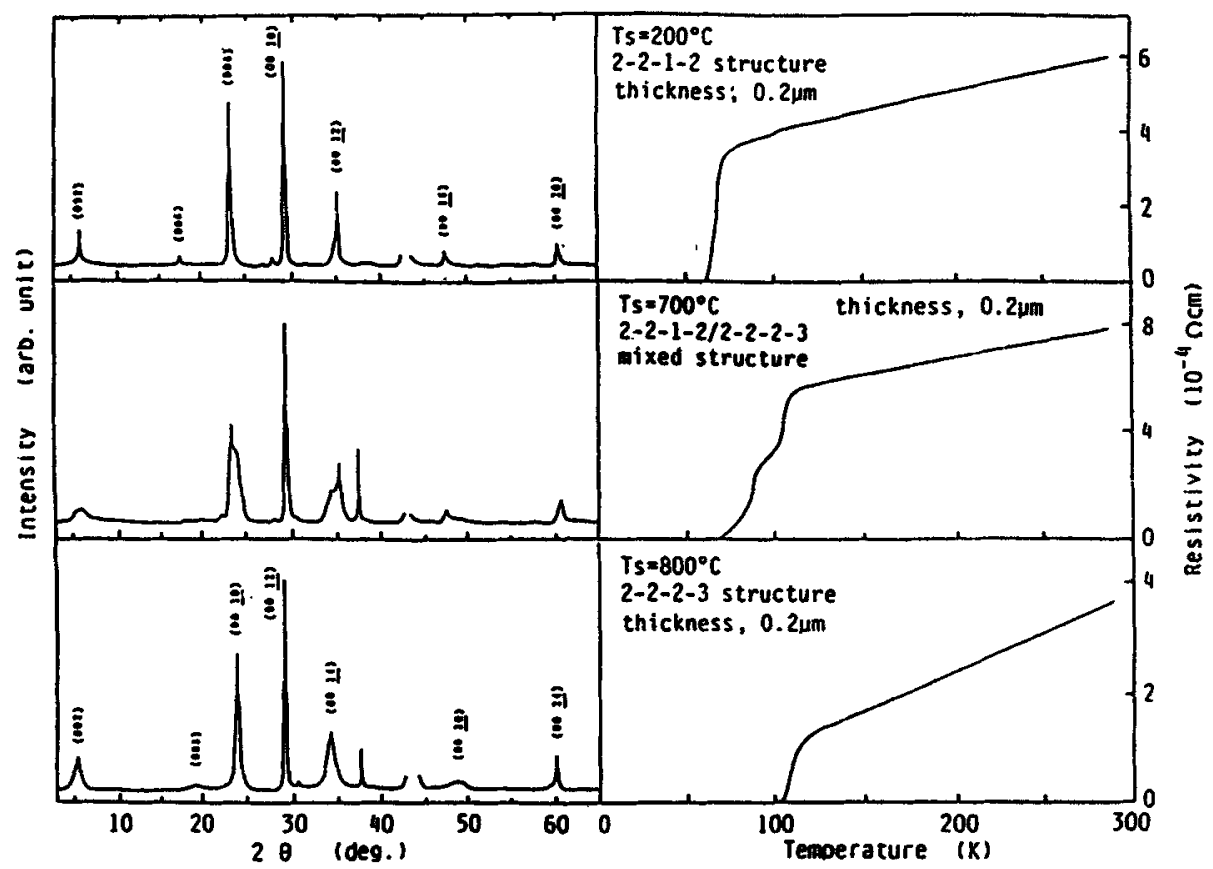

Figure 15. $X$-ray diffraction patterns and resistivity-temperature characteristics for sputtered $\mathrm{B}-\mathrm{Sr}-\mathrm{Ca}-\mathrm{Cu}-\mathrm{O}$ thin films prepared at different substrate temperatures $T_{s}$ using conventional planar magnetron sputter system with $\mathrm{Bi}-\mathrm{Sr}-\mathrm{Ca}-\mathrm{Cu}-\mathrm{O}$ single target.

Table 3. Influence of factors of sputter deposition on sputtered film properties.

\begin{tabular}{|c|c|}
\hline Deposition conditions & Film properties \\
\hline $\begin{array}{l}\text { Growth rate } \\
\text { Temperature } \\
\text { Deposition } \\
\text { Annealing }\end{array}$ & $\begin{array}{l}\text { Composition } \\
\text { Stoichiometry } \\
\text { Off-stoichiometry } \\
\text { Impurity } \\
\text { Uniformity }\end{array}$ \\
\hline $\begin{array}{l}\text { Target } \\
\text { Composition } \\
\text { Configuration }\end{array}$ & $\begin{array}{l}\text { Crystal form } \\
\text { Structure } \\
\text { Grain size }\end{array}$ \\
\hline $\begin{array}{l}\text { Sputter gas } \\
\text { Pressure } \\
\text { Composition } \\
\text { Ionization }\end{array}$ & $\begin{array}{l}\text { Surface morphology } \\
\text { Defects structure } \\
\text { Point defect } \\
\text { Dislocation }\end{array}$ \\
\hline $\begin{array}{l}\text { Substrate } \\
\text { Materials } \\
\text { Position }\end{array}$ & $\begin{array}{l}\text { Stress } \\
\text { Microstress } \\
\text { Macrostress }\end{array}$ \\
\hline $\begin{array}{l}\text { Electrode } \\
\text { Configuration }\end{array}$ & Interface \\
\hline
\end{tabular}




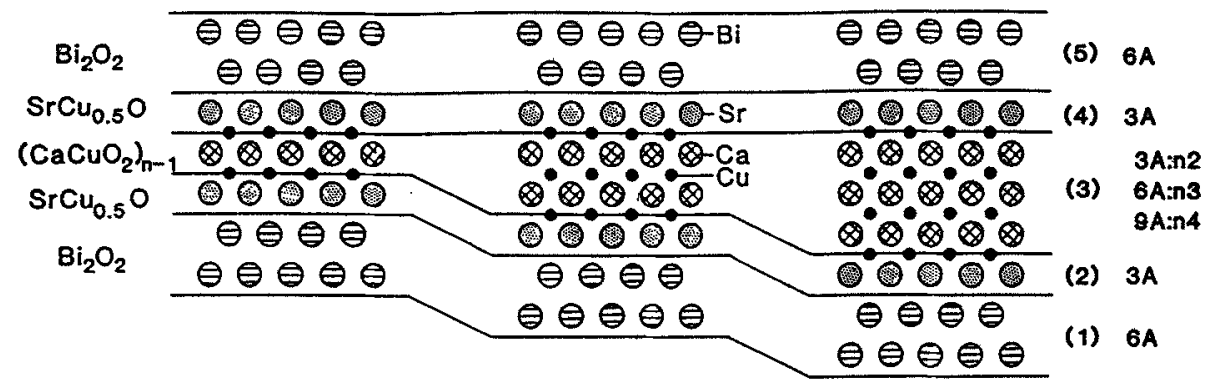

2212

2223

2234

Figure 16. Layer-by-layer deposition of $\mathrm{Bi}-\mathrm{Sr}-\mathrm{Ca}-\mathrm{Cu}-\mathrm{O}$ by multi-target sputter; alternate deposition in the order $(1) \rightarrow(2) \rightarrow(3) \rightarrow(4) \rightarrow(5)$.

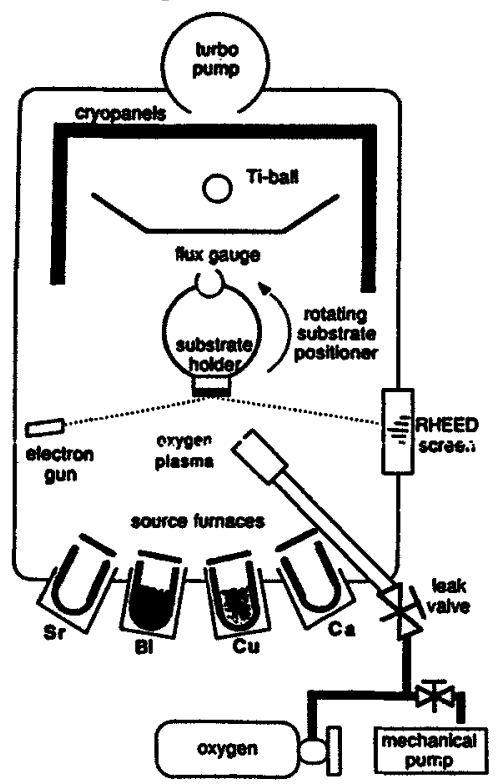

(a)

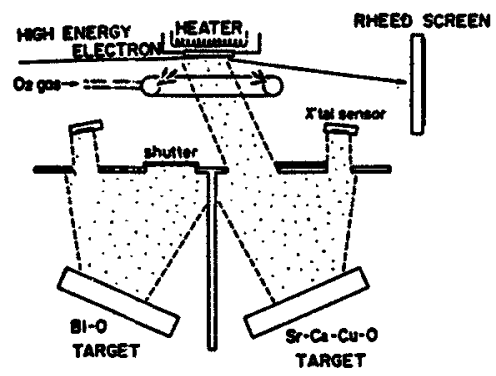

(c)

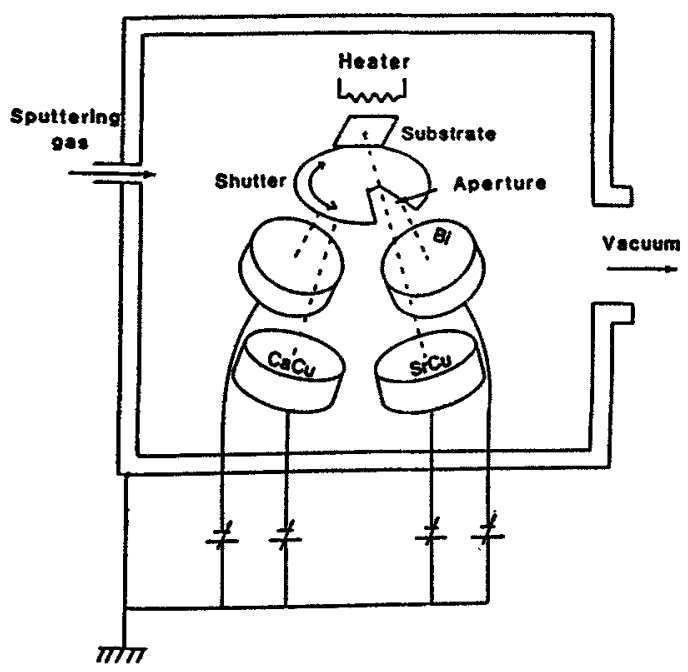

(b)

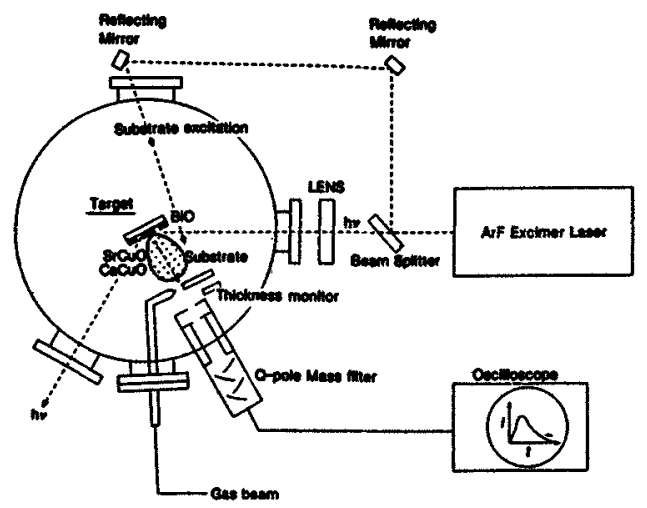

(d)

Figure 17. Layer-by-layer deposition systems: (a) molecular beam epitaxy; (b) multi-target planar magnetron sputter, (c) multi-target ion beam sputter and (d) laser ablation. 
It is reasonably considered that the superconducting phase will be closely controlled if the layered oxides are synthesized on an atomic scale by layer-by-layer deposition as shown in figure 16.

Several processes have been tried for the layer-by-layer deposition including multitarget sputter (Adachi et al 1988), dual ion beam sputter (Fujita et al 1989), laser ablation (Tabata et al 1989) and molecular beam epitaxy (Eckstein et al 1989) as shown in figure 17 . In the multi-target sputter process, the deposition rate is selected

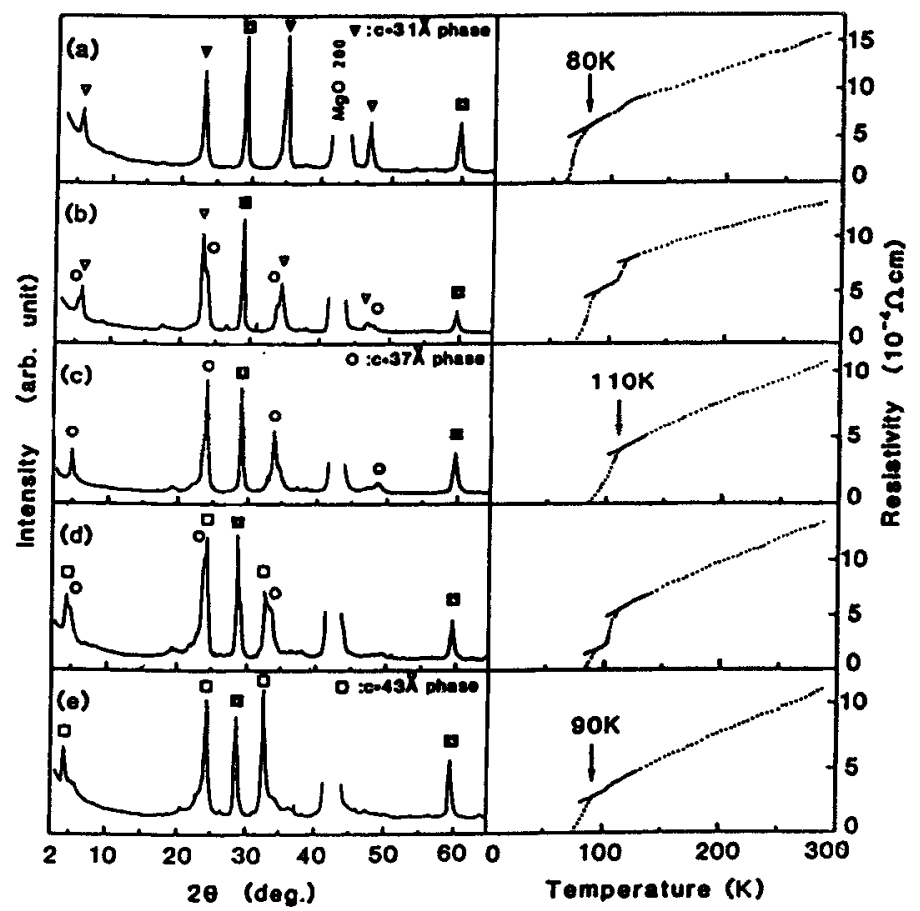

Figure 18. X-ray diffraction patterns with resistivity-temperature characteristics for phase controlled Bi-Sr-Ca-Cu-O thin films of 200-300 $\AA$ thickness: (a) Bi-2212, (b) Bi-2212/2223, (c) Bi-2223, (d) Bi-2223/2234 and (e) Bi-2234.

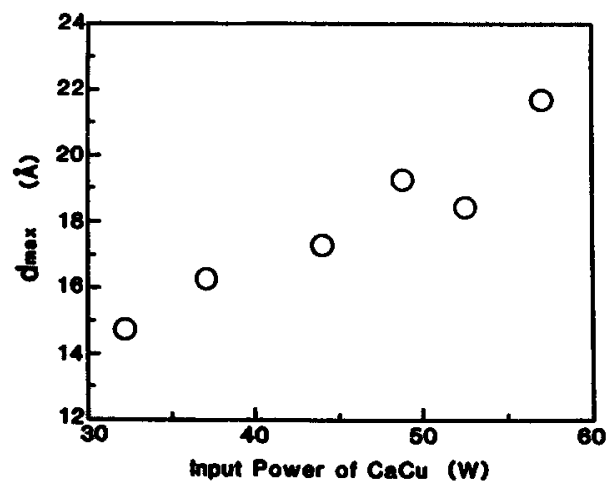

Figure 19. Variation of lattice spacing with input power of $\mathrm{CaCu}$ target obtained for the sputtered $\mathrm{Bi}-\mathrm{Sr}-\mathrm{Ca}-\mathrm{Cu}-\mathrm{O}$ thin films in a multi-target sputter system. 
so as to pile up the $\mathrm{Bi}-\mathrm{O}, \mathrm{Sr}-\mathrm{O}, \mathrm{Cu}-\mathrm{O}$ and $\mathrm{Ca}-\mathrm{O}$ layers in the atomic scale range. The substrate temperature was kept around the crystallizing temperature of $650^{\circ} \mathrm{C}$, as as-sputtered films show a broad superconducting transition. These superconducting properties were improved by post-annealing at 850 to $900^{\circ} \mathrm{C}$. Figure 18 shows the typical superconducting properties of $\mathrm{Bi}$ high-superconducting films fabricated by the layer-by-layer deposition. The superconducting phase is controlled simply by the thickness of $\mathrm{Cu}-\mathrm{Ca}-\mathrm{O}$ during the deposition as shown in figure 19.

\section{Future direction}

\subsection{Future electronics}

Thin films of bulk ceramics could be used as novel materials and/or electronic devices. The sputter process is available for deposition of complex ceramic materials. It is important to understand the influence of factors of sputter deposition on the resultant sputtered films, shown in table 3, so as to achieve controlled deposition of thin films. With the present understanding of the influence of these factors several kinds of electronic devices and/or components are prepared by the sputter process as shown in figure 20: (a) thin films of high temperature semiconductors SiC provide high temperature sensors (Wasa et al 1979); (b) single crystal and/or c-axis oriented $\mathrm{ZnO}$ piezoelectric thin films are produced for surface acoustic wave (SAW) devices used in colour TV and VTR (Yamazaki et al 1980); (c) magnetic heads with narrow magnetic gaps of less than $1 \mu \mathrm{m}$ are provided by sputter deposition of $\mathrm{SiO}_{2}$ (Wasa 1981).

Sputter systems for production have been designed so as to realize a controlled deposition of thin films, including control of film thickness and/or crystal properties.

Figure 21 shows the hemispherical sputter system for deposition of $c$-axis oriented $\mathrm{ZnO}$ thin films with a surface acoustic wave (SAW) transducer quality. The hemispherical target could stabilize the growth of the $c$-axis oriented $\mathrm{ZnO}$ thin films as shown in figure 21 , probably due to reduction of irradiation effects of the highly energetic neutral atoms from the $\mathrm{ZnO}$ target.

The magnetic heads shown in figure 20 have been produced by deposition of $\mathrm{SiO}_{2}$ thin films of $0.15 \mu \mathrm{m}$ thickness on a surface of a pair of ferrite cores followed by cementing them together. Off-axis sputter is introduced to deposit the $\mathrm{SiO}_{2}$ thin films as shown in figure 22 , so as to reduce the thermal and/or plasma irradiation damage of the surface of the ferrite cores. It is important to understand and/or control the irradiation effects of plasma on sputtered thin film electronic devices. To avoid the effects of irradiation of the highly energetic atoms, the sputter gas pressure is raised so as to thermalize the highly energetic atoms due to collisions with the gas atoms. A number of novel thin film materials could be synthesized if we understand the effects of the plasma on sputtered film properties.

Layer-by-layer deposition by the sputter process is not only available for deposition of bulk ceramics on an atomic scale, but also for synthesis of materials comprising superlattice structures.

Figure 23 shows the typical X-ray diffraction spectra from the man-made superlattice of Bi-layered oxide superconductors of $\left(A_{k} B_{k}\right)_{m}$ structure synthesized by layer-by-layer sputter. Unit $\mathrm{A}$ is the crystal structure with double $\mathrm{Cu}-\mathrm{O}$ planes (Bi-2212) and unit $\mathrm{B}$ is the crystal structure with triple $\mathrm{Cu}-\mathrm{O}$ planes (Bi-2223) (Wasa 
Table 4. Summaries of layer-by-layer deposition.

\begin{tabular}{|c|c|c|}
\hline Materials & Preparation & Structure/properties \\
\hline $\begin{array}{l}\text { PbTiO/PbLaTiO } \\
\text { (sapphire) }\end{array}$ & $\begin{array}{c}\text { Multitarget sp. } \\
T_{s}=650^{\circ} \mathrm{C}\end{array}$ & $\begin{array}{l}\text { Superlattice } \\
\text { wavelength; } \\
100-300 \AA\end{array}$ \\
\hline $\begin{array}{l}\mathrm{BiSrCaCuO} \\
(\mathrm{MgO})\end{array}$ & $\begin{array}{c}\text { Multitarget sp. } \\
T_{s}=650^{\circ} \mathrm{C}\end{array}$ & $\begin{array}{l}\text { Phase control } \\
\qquad \mathrm{Cu}-\mathrm{O} \text { layer; } 1-5\end{array}$ \\
\hline $\begin{array}{l}\mathrm{BiSrCaCuO} \\
\text { (ST) }\end{array}$ & $\begin{array}{c}\text { Ion beam sp. } \\
T_{s}=605^{\circ} \mathrm{C} \\
\text { RHEED }\end{array}$ & $\begin{array}{l}\text { Phase control } \\
\quad \mathrm{Cu}-\mathrm{O} \text { layer; } 2-3\end{array}$ \\
\hline $\begin{array}{l}\text { YBaCuO/DyBaCuO } \\
\text { (MgO) }\end{array}$ & $\begin{array}{l}\text { Multitarget sp. } \\
T_{a}=700^{\circ} \mathrm{C}\end{array}$ & $\begin{array}{l}\text { Superlattice } \\
\text { wavelength; } 24 \AA\end{array}$ \\
\hline $\begin{array}{l}\mathrm{Bi}(\mathrm{Pb}) \mathrm{SrCaCuO} \\
(\mathrm{MgO})\end{array}$ & $\begin{array}{l}\text { Laser ablation, } \\
\qquad \begin{array}{l}\text { ArF } \\
T_{s}=580^{\circ} \mathrm{C} \\
\mathrm{N}_{2} \mathrm{O}\end{array}\end{array}$ & $\begin{array}{l}\text { Substitution } \\
\qquad \mathrm{Ca}, \mathrm{Sr} \rightarrow \mathrm{Ba}\end{array}$ \\
\hline $\begin{array}{l}\text { YBaCuO/PrBaCuO } \\
\text { (ST, MgO) }\end{array}$ & $\begin{array}{c}\text { Multitarget sp. } \\
T_{3}=700^{\circ} \mathrm{C}\end{array}$ & $\begin{array}{l}\text { Superlattice } \\
\text { PrBaCuO; } \\
\text { insulating inter- } \\
\text { layers coupling }\end{array}$ \\
\hline $\begin{array}{l}\text { BiSrCaCuO/ } \\
\text { BiSrCuO/ } \\
\text { BiSrCaCuO } \\
(\mathrm{MgO})\end{array}$ & $\begin{array}{c}\text { Multitarget sp. } \\
T_{s}=650^{\circ} \mathrm{C}\end{array}$ & $\begin{array}{l}\text { SNS Josephson junc- } \\
\text { tion } \mathrm{S} ; \mathrm{Bi}-2212 \\
(2000-3000 \AA) \mathrm{N} \\
\text { Bi-2201 }(600 \AA) \\
\text { Shapiro step at } 4 \cdot 2 \mathrm{~K}\end{array}$ \\
\hline $\begin{array}{l}\mathrm{BiSrCaCuO} \\
\text { (ST, MgO) }\end{array}$ & $\begin{array}{l}\text { Reactive ev. } \\
\text { in } \mathrm{O}_{3} \\
T_{s}=550-600^{\circ} \mathrm{C}, \\
\text { RHEED }\end{array}$ & $\begin{array}{c}\text { Phase control } \\
\text { Cu-O layer, } \\
1-3,5\end{array}$ \\
\hline $\begin{array}{l}\text { YBaCuO/PrBaCuO } \\
(\mathrm{MgO})\end{array}$ & $\begin{array}{l}\text { Laser ablation, } \\
\qquad \mathrm{KF} \\
T_{\mathrm{s}}=670^{\circ} \mathrm{C}\end{array}$ & $\begin{array}{l}\text { Superlattice } \\
\text { wavelength; } 24 \AA\end{array}$ \\
\hline $\begin{array}{c}\mathrm{YBaCuO} / \mathrm{PrBaCuO} \\
\left(\mathrm{LaAlO}_{3}\right)\end{array}$ & $\begin{array}{l}\text { Laser ablation, } \\
\qquad \mathrm{KrF} \\
T_{s}=720^{\circ} \mathrm{C}, \mathrm{N}_{2} \mathrm{O}\end{array}$ & $\begin{array}{l}\text { Superlattice inter- } \\
\text { layer coupling }\end{array}$ \\
\hline $\begin{array}{l}\mathrm{BiSr}(\mathrm{Ca}, \mathrm{Y}) \mathrm{CuO} \\
(\mathrm{MgO})\end{array}$ & $\begin{array}{l}\text { Laser ablation, } \\
\text { ArF } \\
\text { postanneal } \\
840^{\circ} \mathrm{C}\end{array}$ & $\begin{array}{l}\text { Superlattice; } \\
\mathrm{Ca} / \mathrm{Y}=1 ; \\
\text { semiconductor } \\
\mathrm{Ca} / \mathrm{Y}=0.85 / 0 \cdot 15 \\
\text { supercon. interlayer } \\
\text { coupling }\end{array}$ \\
\hline
\end{tabular}

et al 1991). The close fits between the calculated X-ray diffraction spectra and the actual ones indicate formation of the artificial superlattices on an atomic scale.

The accuracy of the sputter process for deposition of the superlattice is doubtful, since interdiffusion will take place due to the presence of energetic sputter atoms during film growth. Several experiments have been tried to ascertain the limitations of the controlled deposition on an atomic scale.

It has been found that the sputtered superlattice comprising perovskite super- 


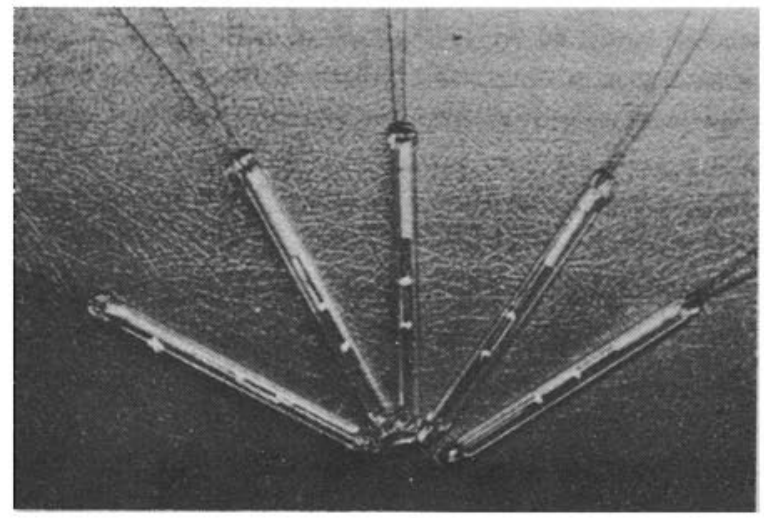

(a)

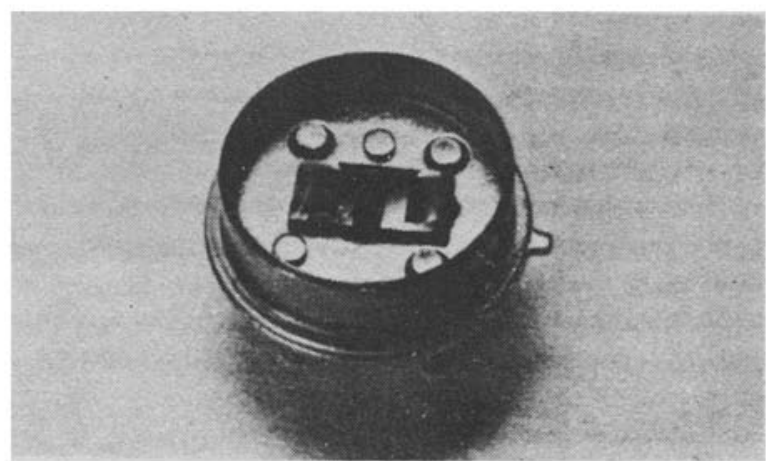

(b)

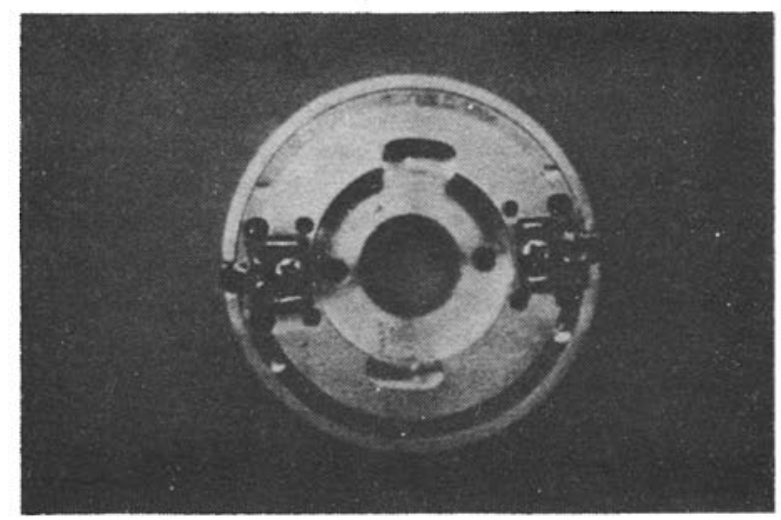

(c)

Figure 20. Typical electronic devices prepared by sputter process: (a) $\mathrm{SiC}$ thin film high temperature sensors; (b) $\mathrm{ZnO}$ thin film surface acoustic devices and (c) magnetic head comprising $\mathrm{SiO}_{2}$ thin film gap of $0.35 \mu \mathrm{m}$ width for video tape recorders. 

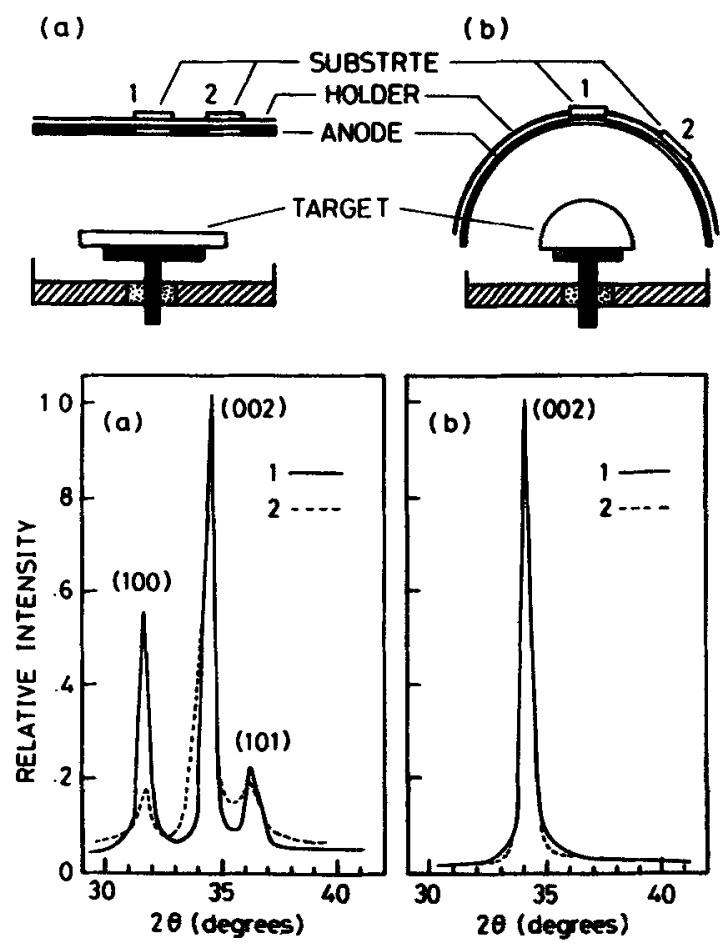

Figure 21. Hemispherical sputter system for the deposition of controlled $c$-axis oriented $\mathrm{ZnO}$ thin films with piezoelectric transducer quality: Electrode configurations and $\mathrm{X}$-ray diffraction patterns. (a) Conventional sputter system and (b) hemispherical system.
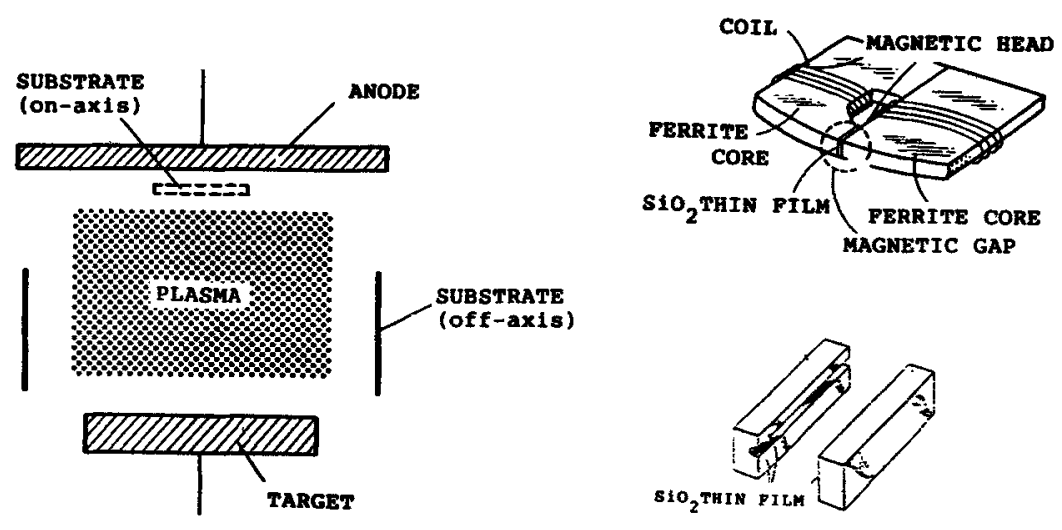

FERRITE CORE

Figure 22. Off-axis sputter system for the production of magnetic heads with narrow $\mathrm{SiO}_{2}$ magnetic gap for video tape recorders.

conductors of $\mathrm{Bi}-2212$ and $\mathrm{Bi}-2201$ can be made by the multi-target sputter system using B-2212 and Bi-2201 targets. The sputtered atoms were thermalized under high sputter gas pressure. The controlled wavelength which indicates the accuracy of the sputter process is found to be as short as in the nanometre range (Matsushima et al 


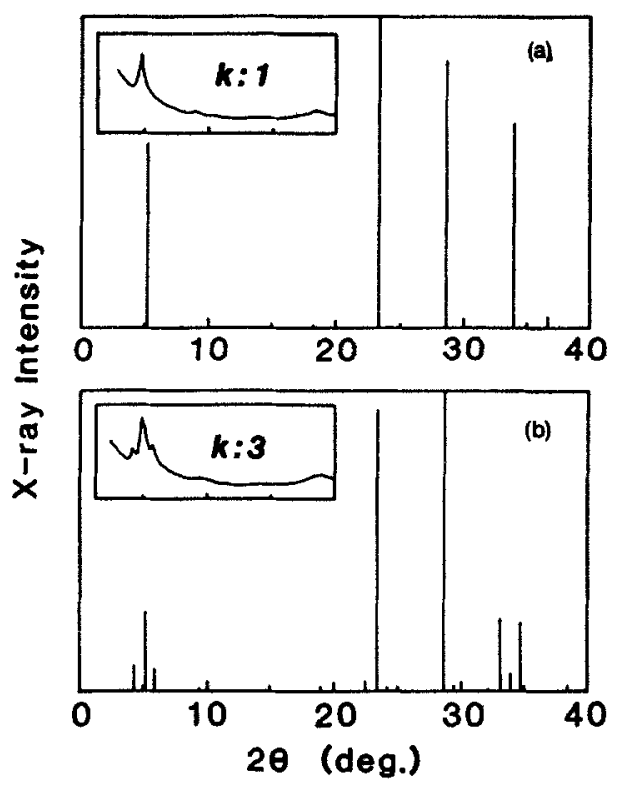

Figure 23. Calculation and experimental X-ray diffraction spectra from artificially made Bi-layered oxides comprising $\left(A_{k} B_{k}\right)_{m}$ superlattices, where unit $A$ is the crystal structure with double $\mathrm{Cu}-\mathrm{O}_{2}$ layers and unit $\mathrm{B}$ is the crystal structure with triple $\mathrm{Cu}-\mathrm{O}_{2}$ layers; (a) $k=1$ and (b) $k=3$.

1990). The accuracy of the sputter process allows one to make a Josephson junction of S/N/S structure (Mizuno et al 1989)*.

Table 4 shows the summaries of these experiments on compound oxides of perovskite structure. This indicates that the sputter process offers the possibility of making future electronic devices, including optical waveguide devices (Wasa et al 1984), acousto devices (Setsune et al 1983), high- $T_{c}$ superconducting devices (Wasa et al 1991), and ferroelectric memories (Carrano et al 1989).

\subsection{Environmental quality}

Environmentally friendly materials and/or processing are important to find solutions to the current environmental issues. Saving of processing energy and materials, waste minimization, and reduction of toxic materials should be considered in future industry. Thin film materials and devices are essentially available for minimization of toxic materials since the quantity of the toxic materials used is limited only to the surface

* The mean free path $\lambda_{1}$ of the atoms in the gas molecules is given by

$$
\lambda_{1} \simeq 1 / \pi\left(r_{1}+r_{2}\right)^{2} n_{2},
$$

where $r_{1}$ and $r_{2}$ are the atomic radii of sputtered atoms and sputter gas molecules respectively, and $n_{2}$ is the density of sputter gas molecules. In the case of Ar ion bombardment of copper target, taking $r_{1}=0.96 \times 10^{-8} \mathrm{~cm}, r_{2}=1.82 \times 10^{-8} \mathrm{~cm}$, and $n_{2}=3.5 \times 10^{16} / \mathrm{cm}^{3}, \lambda_{1}$ becomes $11.7 \times 10^{-3} \mathrm{~cm}$ (at $0^{\circ} \mathrm{C}$, 1 torr).

For target-substrate spacing of $10 \mathrm{~cm}$, the average collision numbers will be around 10 times at sputter gas pressure of $1 \times 10^{-2}$ torr. 


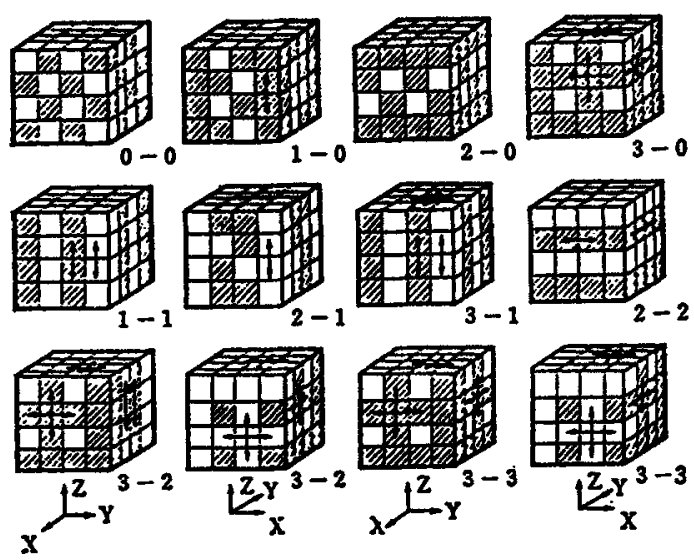

Figure 24. Nanometre composites for future electronic devices which could be prepared by the sputter process.

and/or thin film layer. The sputter process could reduce bulk toxic industrial materials since a wide variety of bulk industrial materials could be deposited. Electronic materials and/or devices with environmental-friendly quality can be produced by the sputter process. Atomically controlled sputter has the possibility of synthesis of man-made materials and/or devices, including superlattices and nanometre composites, as shown in figure 24 , materials without toxic materials.

\section{Acknowledgement}

The author wishes to thank $\mathrm{H}$ Mizuno and S Horiuchi for constant encouragement.

\section{References}

Adachi H, Kawaguchi T, Setsune K, Ohji K and Wasa K 1983 Appl. Phys. Lett. 42867

Adachi H, Mitsuyu T and Wasa K $1986 \mathrm{~J}$ : Appl. Phys. 60736

Adachi H, Kohiki S, Setsune K, Mitsuyu T and Wasa K $1988 \mathrm{Jpn}$. J. Appl. Phys. 27 L1883

Adachi H and Wasa K 1990 Mater. Res. Soc. Symp. Proc. 200103

Aisenberg S and Chabot R 1971 J. Appl. Phys. 422953

Behrisch R (ed.) 1981 Sputtering by particle bombardment I (Berlin: Springer Verlag)

Carrano J, Sudhama C, Lee J and Miller W 1989 International electron device meeting proc., Washington DC, IEDM89-255

Chopra K L 1969 Thin film phenomena (New York: McGraw Hill)

Eckstein J N et al 1989 J. Vac. Sci. Technol. B 319

Fujita J, Tatsumi T, Yoshitake T and Igarashi H 1989 Appl. Phys. Lett. 542364

Haertling G H and Land C E 1971 J. Am. Ceram. Soc. 541

Kitabatake M and Wasa K 1985 J. Appl. Phys. 581693

Kitabatake M and Wasa K $1988 \mathrm{~J}$. Vac. Sci. Technol. A6 1793

Maissel L and Glang R (eds) 1970 Handbook of thin film technology (New York: McGraw Hill)

Matsushima T, Ichikawa Y, Adachi H, Setsune K and Wasa K 1990 Solid State Commun. 761201

Mizuno K, Higashino H, Setsune K and Wasa K 1989 2nd Inter. symp. on superconductivity, proc. ISS89

Nakagawa T, Yamaguchi J and Hamakawa Y 1982 Jpn. J. Appl. Phys. 21655

Oikawa M and Tada K 1989 Appl. Phys. Lett. 29491

Otsubo S, Maeda T, Minamaikawa T, Yonezawa Y, Morimoto A and Shimizu T 1990 Jpn. J. Appl. Phys. $29 \mathrm{~L} 133$ 
Setsune K, Mitsuyu T, Yamazaki O and Wasa K 1983 Ultrason. symp. proc., Atlanta, p. 467

Tabata H, Kawai T, Kanai M, Murata O and Kawai S 1989 Jpn. J. Appl. Phys. 28 L823

Wasa K and Hayakawa S $1976 \mathrm{Jpn}$. Patent 51-84840

Wasa K, Tohoda T, Kasahara Y and Hayakawa S 1979 Rev. Sci. Instrum. 501084

Wasa K 1981 U.S. Patent 4, 288, 307

Wasa K, Yamazaki O, Adachi H, Kawaguchi T and Setsune K 1984 J. Lightwave Technol. LT-2 710

Wasa K, Adachi H, Hirochi K, Ichikawa Y, Matsushima T and Setsune K 1991 J. Mater. Res. 61595

Wasa K and Hayakawa S 1991 Handbook of sputter deposition technology (New Jersey: Noyes)

Wehner G K 1955 Advances in electronics and electron physics (New York: Academic Press) Vol. VII

Yamazaki O, Mitsuyu T and Wasa K 1980 IEEE Trans. Sonics and Ultrason. SU-27 369 